\title{
A UNIVERSIDADE EM AÇÃO: ENSINO, FORMAÇÃO E EXTENSÃO NO FESTIVAL DA PRIMAVERA DA UEMG
}

Aline Choucair Vaz ${ }^{1}$

Amanda Tolomelli Brescia²

\section{RESUMO}

Este artigo versa sobre o I Festival da Primavera, realizado no âmbito da Universidade do Estado de Minas Gerais, em 2019. Os objetivos são avaliar o evento e promover reflexões para aprimorá-lo, pensando em projetos educacionais inovadores que aperfeiçoem o ensino, a extensão e a pesquisa na docência universitária, além da utilização do conceito principal de Moscovici (2003) para analisar as representações sociais dos participantes. A coleta dos dados ocorreu por questionário on-line, enviado a posteriori aos participantes. Os resultados apontam que o evento é um espaço importante para debates, mas ressaltam pontos a serem melhorados em sua realização.

Palavras-chave: Festival Universitário. Comunidade. Extensão.

\footnotetext{
${ }^{1}$ Doutora em Educação pela Universidade Federal de Minas Gerais - FaE/UFMG. Pós Doutora pelo Programa de Pós-Graduação em Educação - Educação e Formação Humana - da Faculdade de Educação da Universidade do Estado de Minas Gerais. Professora da Faculdade de Educação da Universidade do Estado de Minas Gerais $\mathrm{FaE} / \mathrm{CBH} / \mathrm{UEMG}$. Coordenadora do Núcleo de Estudos e Pesquisas sobre Conhecimento e Educação - COED da FaE/CBH/UEMG ORCID: http://orcid.org/0000-0001-5123-768X. E-mail: alinechoucair@gmail.com.

${ }^{2}$ Doutora em Educação pela Universidade Federal de Minas Gerais - FaE/UFMG. Professora da Faculdade de Educação da Universidade do Estado de Minas Gerais FaE/CBH/UEMG. Integra o Núcleo de Estudos e Pesquisas sobre Conhecimento e Educação - COED da FaE/CBH/UEM. ORCID: http://orcid.org/0000-0002-1578-1474. Email: atolomellibrescia@gmail.com.
} 


\section{THE UNIVERSITY IN ACTION: EDUCATION, FORMATION AND OUTREACH IN THE UEMG SPRING FESTIVAL}

\section{ABSTRACT}

This is an article about the UEMG Springtime Festival, which took place in the Minas Gerais State University in 2019. The goals are to evaluate the event and to promote reflections in order to bolster it, by thinking of educational projects that enhance teaching, outreach and research in scholarship, also using Moscovici's (2003) main concept to analyze the social representation of participants. The data was collected through an online survey. The results show that the event is an important space for debate, although there is room for improvement in its organization.

Keywords: University Festival. Community. Outreach.

\section{LA UNIVERSIDAD EN ACCIÓN: ENSEÑANZA, FORMACIÓN Y EXTENSIÓN EN EL FESTIVAL DE PRIMAVERA UEMG}

\section{RESUMEN}

Este artículo trata sobre el Festival de Primavera celebrado en la Universidad del Estado de Minas Gerais en 2019. Los objetivos son evaluar el evento y promover reflexiones para mejorarlo, pensando enproyectos educativos innovadores que mejoren la docencia, extensión e investigación en la docencia universitaria, además del uso del concepto principal de Moscovici (2003) para analizar las representaciones sociales de los participantes. La recopilación de datos se produjo mediante cuestionario on-line (en línea). Los resultados indican que el evento es unespacio importante para los debates, pero destacan los puntos a mejorar en su realización.

Palabras clave: Festival Universitario. Comunidad. Extensión. 


\section{INTRODUÇÃO}

Este artigo objetiva analisar a organização, a realização e a avaliação de participantes e proponentes das atividades do I Festival da Primavera da Universidade do Estado de Minas Gerais (UEMG), que aconteceu no âmbito da Universidade, no mês de outubro de 2019, na cidade de Belo Horizonte, Minas Gerais, Brasil. Objetiva também pensar o Festival como sendo um projeto inovador, que tentou aliar ensino, extensão e pesquisa e refletir acerca da formação universitária. Ele surgiu da percepção da necessidade de refletir sobre a Universidade e sua expansão à comunidade como sendo uma ação de essencial valor aos estudantes, de graduação e pós-graduação, e aos professores, que enxergam na docência uma possibilidade de diálogo com as várias instâncias sociais para além dos muros institucionais.

Ao tratar dos festivais de forma geral, observa-se que esses têm sido objeto de análise dos diferentes campos de conhecimento, majoritariamente, da Arte, da Educação Física e da História. Em pesquisa realizada em bancos de estudos e na internet, observou-se a incidência de festivais de ginástica, dança, música, audiovisual, além de alguns relacionados à cultura popular e ao patrimônio, promovidos por diferentes Prefeituras, em âmbito regional. No caso das Universidades, os festivais se firmam como uma tradição, inclusive como eventos renomados, relacionados aos períodos de recesso acadêmico e à possibilidade de maior aprofundamento nas atividades oferecidas, como acontece na Universidade Federal de Minas Gerais (UFMG) e na Universidade Federal de Ouro Preto (UFOP). Seus tradicionais Festivais de Inverno e de Verão são caracterizados pela oferta de atividades de extensão do mundo acadêmico e científico, tendo, em sua profundidade, o peso daquelas relacionadas à Arte e também ao mundo das corporeidades e das culturas populares.

Kaminski (2016) ao pesquisar os Festivais de Inverno da cidade de Ouro Preto, Minas Gerais, ocorridos no período de 1967 a 1979, analisa que o Festival tornou-se um lugar privilegiado de reunião da contracultura daquele momento. Artistas, jovens, estudantes, intelectuais participavam do palco do Festival também 
como crítica estética e política, em um momento marcado pela Ditadura Militar - e, por isso foi lugar de repressão dos órgãos governamentais:

O comportamento de parte dos jovens que participavam do Festival de Inverno chocava as autoridades e os setores mais conservadores de Ouro Preto. Não demorou, o desbunde, a boemia e o consumo de drogas começaram a ser reprimidos na cidade. Atentos ao caráter subversivo das propostas de mudanças comportamentais, os órgãos de repressão passaram a coibir certas manifestações, ação normalmente justificada pelo combate às drogas (KAMINSKI, 2016, p. 345).

Kaminski (2016) destaca o caráter revolucionário e de questionamento do status quo que os festivais ganham ao longo da nossa história. As participações de intelectuais e juventudes, sobretudo as universitárias, cotejam contornos de questionamento do governo vigente e das ações consideradas de conformação das desigualdades sociais, seja no plano comportamental, seja no político.

Reis e Bomfim (2012) destacam a importância dos componentes do patrimônio, da memória e da identidade presentes nos Festivais de Inverno de Ouro Preto. Os autores mostram que o caráter de inquirição de valores presentes socialmente se interliga aos festivais, no entanto, é possível vê-lo com mais precisão em contextos políticos de maior censura ou repressão social, como na Ditadura. Em momentos de maior liberdade política, os festivais servem para referendar a cidade, sua produção e importância social e histórica, como no caso da cidade de Ouro Preto, além de emocionar e voltar a cidade para a importância da preservação da memória local e de seus moradores e suas culturas.

Neste bojo de discussões, os festivais têm sentidos de festa, demonstrações, estudos e, dependendo de sua natureza, competições. Arrebanham a comunidade presente, seja para valorizar a política local ou questioná-la. Em se tratando de competições esportivas, valorizam uma especialidade atlética ou esportiva local, projetando uma imagem sobre os seus envolvidos. 
Nas Universidades ganham também um aspecto formador para lidar com a extensão do conhecimento científico e o seu caráter revolucionário. A perspectiva interdisciplinar neste mister tem um cenário importante. Por mais específicos que sejam, os festivais lidam com a comunidade e com as múltiplas demandas dos sujeitos envolvidos. O conhecimento é a bússola de compasso desta narrativa.

Na perspectiva da Arte, Bredariolli (2009, p. 36) destaca que a "interculturalidade, a interação entre as diferentes culturas, assim como [a] interdisciplinaridade, são conceitos que integram o conjunto das características do ensino de arte pós-moderno", presentes atualmente nos Festivais de diferentes matizes, sobretudo de natureza científica, como é o caso das Universidades. A ideia de arte-educação, assim como outros saberes que vêm da Academia científica, foi o pilar para a construção do I Festival da Primavera da UEMG.

\section{A UNIVERSIDADE DO ESTADO DE MINAS GERAIS E SUA PROPOSTA DE ENSINO, PESQUISA E EXTENSÃO}

A Universidade do Estado de Minas Gerais (UEMG) foi criada pelo Art. 81 da Constituição do Estado de Minas Gerais de 1989, como uma autarquia, prevendo também o funcionamento da Reitoria na capital e de Unidades Acadêmicas em diversas regiões do Estado. Na estrutura do Estado, atualmente a Universidade vincula-se à Secretaria do Estado de Educação, à qual compete formular e implementar políticas públicas que assegurem 0 desenvolvimento científico e tecnológico, a inovação e o ensino superior no Estado. E, sua Reitoria está sediada no $8^{\circ}$ andar do prédio Minas, da Cidade Administrativa do Estado de Minas Gerais.

O processo de organização do modelo multicampi da UEMG centrou-se, num primeiro momento, em aperfeiçoar o ensino de graduação e, posteriormente, aperfeiçoar e ampliar os programas de pós-graduação lato sensu, contando com a qualificação e experiência de docentes da UEMG e de outras universidades. Novas demandas da sociedade levaram a UEMG a aprofundamentos de 
novos estudos e pesquisas em áreas para as quais ela identificou possibilidades de avanços. Na década de 1990, essa constatação levou a instituição a investir em capacitação do pessoal docente, implementação de linhas e grupos de pesquisa e de extensão, bem como em criação de Programas de Pós-graduação lato sensu.

A estrutura da UEMG foi definida pela Lei $n^{\circ} 11.539$, de 22 de julho de 1994, sendo seu Estatuto aprovado pelo Decreto $n^{\circ}$ 36.898, de 24 de maio de 1995, e seu reconhecimento feito pelo Conselho Estadual de Educação, por meio de publicação no "Minas Gerais", órgão oficial do Estado, em 28 de fevereiro de 1996. A UEMG tem como missão, descrita em seu site oficial, "promover o Ensino, a Pesquisa e a Extensão de modo a contribuir para a formação de cidadãos comprometidos com o desenvolvimento e a integração dos setores da sociedade e das regiões do Estado" (UEMG, 2019c).

O campus Belo Horizonte também teve sua estrutura definida pela Lei $n^{\circ} 11.539 / 1994$, que autorizou a incorporação à UEMG: da Fundação Mineira de Arte Aleijadinho (FUMA), hoje transformada em duas escolas: Música e Design; da Fundação Escola Guignard; do curso de Pedagogia do Instituto de Educação de Minas Gerais (IEMG), que foi transformado no curso de Pedagogia da Faculdade de Educação; e do Serviço de Orientação e Seleção Profissional (SOSP) - hoje, Centro de Psicologia Aplicada (CENPA).

Nove fundações do interior do estado de Minas Gerais passaram a ser denominadas Fundações Agregadas e estão localizadas nos campi regionais. A Lei Delegada 91, de 29 de janeiro de 2003, definiu a estrutura orgânica básica da UEMG e o Decreto $n^{\circ} 43.579$, de 11 de setembro de 2003, estabeleceu as competências das unidades administrativas.

Nos campi do estado de Minas Gerais (2019), a UEMG possui 118 cursos de graduação, distribuídos em 20 campi, que atuam na formação de aproximadamente 22.000 alunos, e empregam 1.647 professores e 608 técnicos administrativos. Além disso, conta com 27 cursos de especialização, 8 mestrados e 2 doutorados. A UEMG também se faz presente com polos de Educação a Distância (EaD) em 6 municípios mineiros. 
A Faculdade de Educação (FaE-CBH-UEMG), local onde o Festival da Primavera foi pensado, organizado e parcialmente realizado, desenvolve atividades de ensino, pesquisa e prestação de serviços à comunidade, sobretudo no tocante à formação e ao aperfeiçoamento de profissionais na área da Educação, além de ofertar o Curso de Pedagogia. Tal curso se destina à formação de profissionais para atuar na docência da Educação Infantil e dos Anos Iniciais do Ensino Fundamental. Conhecimentos sobre gestão são oferecidos como subsídio à compreensão e ao exercício da função de gestor na docência, no planejamento, na pesquisa, na coordenação e na avaliação da ação educativa em espaços escolares e não escolares. O I Festival da Primavera de 2019 foi pensado originalmente no Núcleo de Estudos e Pesquisas sobre Conhecimento e Educação (COED), grupo de pesquisa da FaE-CBHUEMG, criado em 2007, e que tem como finalidade desenvolver investigações sobre o conhecimento, numa perspectiva abrangente, dialogal e contemporânea, com propostas de interlocuções referentes a concepções sobre o conhecimento como instância cultural e investigação de tais relações com a prática educacional. Essa proposta buscou abranger toda a UEMG, congregando, assim, esse aspecto macro que a Universidade hoje possui uma enormidade de cursos com efetivo alcance social nas cidades de Minas Gerais.

\section{FESTIVAL DA PRIMAVERA DA UEMg - PERCEPÇÕES POLÍTICAS E DE DEFESA DO CONHECIMENTO CIENTÍFICO NA SOCIEDADE}

A Universidade se consolida por três aspectos fundamentais que não se dissociam: ensino, pesquisa e extensão. Gonçalves (2015, p. 1249) pontua que:

O princípio da indissociabilidade entre Ensino, Pesquisa e Extensão não pode ser pensado de forma isolada, como fim em si mesmo. Ele decorre de discussões acerca da consolidação de determinado projeto de Universidade, cuja 
formação e produção de conhecimento dialogassem de forma mais ativa e dialógica com os demais segmentos da sociedade. Assim, esse princípio envolve uma dupla perspectiva sobre sua presença e desenvolvimento na Universidade.

Ao pensar a importância de um festival da UEMG, entendeuse que poderia ser uma estratégia importante a interligação das atividades de ensino desenvolvidas na Universidade com as de pesquisa e extensão - o conhecimento produzido pela pesquisa e o ensino divulgados para vários setores da sociedade - que não estão na Academia Científica, mas que muito poderiam contribuir nos debates e ações promovidas.

Desta forma, o COED apresentou, no primeiro semestre de 2019, um projeto ao Programa de Extensão da Universidade denominado Construção de eventos acadêmicos e culturais: teoria e prática de um festival da primavera na UEMG. O objetivo desse projeto inovador era investigar o processo de construção de um festival acadêmico e cultural, propor e executar um protótipo na UEMG, o I Festival da Primavera UEMG 2019. Era necessário fazer a Universidade se firmar nas representações sociais em Minas Gerais e no Brasil, no que tange aos grandes eventos acadêmicos. Pode se inferir o conceito de representações sociais em Moscovici (2003), por meio da constituição e do reforço das identidades dos grupos e das práticas relacionadas a estes.

Esse projeto, desde o final do ano de 2018, foi objeto de debate e discussões do grupo de pesquisa e extensão (COED), no qual a temática primeiramente foi circunscrita na perspectiva de refletir sobre os desafios da globalização e do conhecimento mediado pelas mídias sociais, mas depois se voltou ao slogan "Quem sabe? A Universidade em Ação!".

O debate em torno dessa proposta foi algo que consumiu muitos encontros e discussões do grupo, porque, embora a primeira opção seja reveladora dos desafios do século XXI, a maioria dos integrantes queria dar ao tema principal dois princípios importantes: um caráter abrangente de apresentação de propostas mais gerais sobre o conhecimento (inclusive por ser o primeiro Festival da 
Universidade) e uma perspectiva mais política acerca da importância social do conhecimento científico.

No ano de 2018, com a entrada do governo do presidente Jair Bolsonaro na esfera federal, o discurso de desqualificação e negação da Ciência tem sido incentivado pelos próprios órgãos governamentais. Além de verbas cortadas, o governo atual refuta o conhecimento científico, apontando a supremacia do conhecimento religioso para as realidades sociais. ${ }^{3}$ As Universidades têm sido alvo de ataques dos admiradores do atual Presidente, inclusive do exMinistro da Educação, ${ }^{4}$ Abraham Weintraub, que cortou verbas e classificou como "balbúrdia" nas instituições os eventos que questionavam o atual governo.

Esse cenário tenso, de ataque ao conhecimento científico e desestabilização dos docentes e da pesquisa no Brasil, juntamente com um movimento de perseguição de professores, intelectuais, jornalistas e artistas que se opõem ao desmonte da educação pública, fez o grupo de professores que organizaram o Festival refletir sobre a importância da divulgação e da ação que o conhecimento pode promover num evento de caráter extensionista. Era de fundamental importância que o Festival fosse aberto a toda comunidade, acadêmica ou não. Para tal, haveria de ter atividades gratuitas àqueles que se interessassem e uma comunicação que fosse concretizada, sobretudo, pelas mídias sociais, como Facebook (com página própria), Instagram, Twitter, entre outras.

As atividades propostas para a comunidade seriam feitas pelos próprios estudantes e professores. Para tanto, foi aberto um edital para submissão das propostas e apreciação de sua finalidade e importância para o evento. A equipe avaliou as propostas pensadas, e foi perceptível a participação de muitos estudantes, principalmente, e professores que se propuseram a desenvolver atividades na semana de recesso, em outubro de 2019.

O COED tinha em perspectiva que escolher um recesso para a realização do festival poderia facilitar a participação de estudantes e professores da Educação Básica, justamente por ser um período

${ }^{3}$ Cf. LEITE, 2019.

${ }^{4}$ Cf. AGOSTINI, 2019. 
em que estes teriam um tempo de dedicação maior às atividades. Outro ponto importante foi o voluntariado no evento, que contou com os professores componentes do núcleo de pesquisa do COED, mas também de estudantes que quiseram participar da organização da atividade e da recepção dos convidados nos locais indicados para a realização dos vários eventos concomitantes.

O Festival ocorreu entre 16 e 18 de outubro de 2019, em Belo Horizonte, nas Unidades da UEMG da capital, assim como em outros espaços públicos sinalizados pelos proponentes, como praças públicas e academias de dança. Em sua logomarca, a equipe quis valorizar a Primavera como símbolo de mudança e florescimento, melodias, por meio do olhar científico e também dos saberes populares:

Figura 1 - Logomarca feita pela equipe de organização do Festival

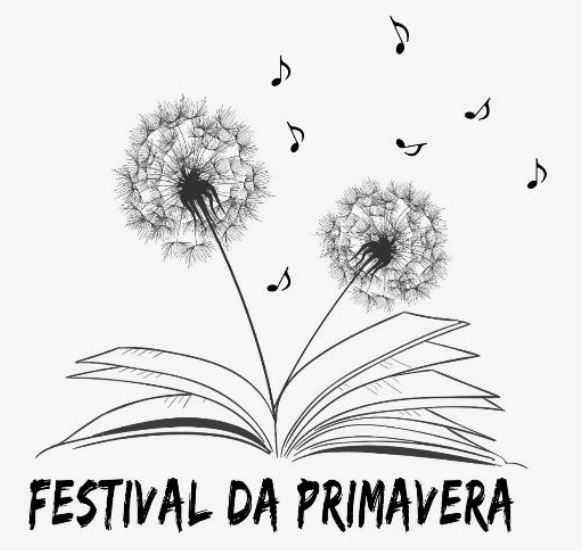

Fonte: UEMG, 2019b.

Sem a hierarquização dos saberes, a Arte está estampada no evento, por meio da música, da criação e da possibilidade que a primavera tem de reunir o florescimento e a ação - que é o tema do evento. Assim, sob este olhar, aconteceu o primeiro Festival da Universidade. As atividades dos três dias tiveram como marca as proposições aceitas por meio do edital, conforme está presente nesta reprodução da programação (UEMG, 2019a): 
Dia 16 de outubro de 2019

\begin{tabular}{|c|c|}
\hline Atividade & Inscritos \\
\hline $\begin{array}{l}\text { LIBRÁRIO NA EDUCAÇÃO: Jogo de incentivo a Libras com } \\
\text { empatia }\end{array}$ & 30 \\
\hline Mulheres, classe e raça: um diálogo sobre interseccionalidade & 40 \\
\hline Crochê e ativismo & 35 \\
\hline OCUPA FAE: TIRE A FAE DO QUADRADO! & 40 \\
\hline Água para beber. Água para viver & 26 \\
\hline Libras para iniciantes & 35 \\
\hline $\begin{array}{l}\text { "O CONTO QUE AS CAIXAS CONTAM" e "ATELIÊ DE } \\
\text { FORMAÇÃO: possibilidades de uso da biblioteca escolar para a } \\
\text { formação do leitor crítico e a inclusão" }\end{array}$ & 60 \\
\hline Abertura do $1^{\circ}$ Festival da Primavera & 55 \\
\hline
\end{tabular}

\section{Dia 17 de outubro de 2019}

\begin{tabular}{|l|c|}
\hline \multicolumn{1}{|c|}{ Atividade } & Inscritos \\
\hline $\begin{array}{l}\text { O uso político da arte: a música na Ditadura militar brasileira e } \\
\text { o cinema nazista }\end{array}$ & 40 \\
\hline Experimentos Interativos de Ciências & 40 \\
\hline OCUPA FAE: TIRE A FAE DO QUADRADO! & 13 \\
\hline Dicionarizando com colagem & 20 \\
\hline Livro das Árvores dos Ticuna e do livro Árvores Brasileiras & 35 \\
\hline $\begin{array}{l}\text { Spice taste of India: Experiências profissionais de designers na } \\
\text { Ásia }\end{array}$ & 51 \\
\hline Você já pensou em ser uma família acolhedora? & 32 \\
\hline Artesanato e decoraç̃̃es de sala infantil & 35 \\
\hline Roda de brincadeiras & 20 \\
\hline $\begin{array}{l}\text { Contação de História em Libras - Vivenciando um artefato da } \\
\text { Cultura Surda }\end{array}$ & 25 \\
\hline $\begin{array}{l}\text { O estudo de desenhos animados como estratégias para a sala } \\
\text { de aula na Educação Infantil e em séries iniciais do Ensino } \\
\text { Fundamental }\end{array}$ & 15 \\
\hline
\end{tabular}

\section{Dia 18 de outubro de 2019}

\begin{tabular}{|l|c|}
\hline \multicolumn{1}{|c|}{ Atividade } & Inscritos \\
\hline Vamos brincar lá fora? A criança nos espaços urbanos & 20 \\
\hline OCUPA FAE: TIRE A FAE DO QUADRADO! & 8 \\
\hline Brincar com palavras & 20 \\
\hline
\end{tabular}




\begin{tabular}{|l|c|}
\hline A Magia das Bolhas de Sabão Gigantes & 40 \\
\hline Árvore Nômade & 10 \\
\hline $\begin{array}{l}\text { Apresentação de canções a solo, voz e violão, dentro da } \\
\text { estética de música popular brasileira }\end{array}$ & 19 \\
\hline Sessão Cine UEMG & 57 \\
\hline Introdução e noções básicas de Primeiros Socorros & 35 \\
\hline O Casaco de Marx & 20 \\
\hline $\begin{array}{l}\text { A vivência-poética enquanto processo educativo por meio do } \\
\text { processo de escrita e da arte do bordado }\end{array}$ & 25 \\
\hline Árvore Nômade & 8 \\
\hline $\begin{array}{l}\text { O estudo de desenhos animados como estratégias para a sala } \\
\text { de aula na Educação Infantil e em séries iniciais do Ensino }\end{array}$ & 15 \\
\hline $\begin{array}{l}\text { Fundamental } \\
\text { Primavera da dança do bairro São Geraldo }\end{array}$ & 51 \\
\hline
\end{tabular}

De 16 a 18 de outubro de 2019

\begin{tabular}{|c|c|}
\hline \multicolumn{1}{c|}{ Atividade } & Inscritos \\
\hline Saberes pelas mãos & 26 \\
\hline
\end{tabular}

Essa programação aconteceu, em sua maioria, no espaço físico da Faculdade de Educação da UEMG, também contando com atividades na Escola de Design, na Reitoria (Cidade Administrativa), na Praça da Liberdade, em outra praça localizada em frente à Faculdade de Educação, Campus Belo Horizonte, e numa academia de dança. Com essa programação diversificada, procurou-se chegar num público para além do universitário, com a abertura para qualquer pessoa inscrita. A seguir será apresentado o Festival sob o olhar do outro.

\section{O OLHAR DO OUTRO SOBRE O FESTIVAL}

Chamou-se aqui de "outro" os participantes que estiveram em, pelo menos, uma das atividades desenvolvidas durante o I Festival da Primavera da UEMG. Inicialmente, será feita a caracterização desse "outro", desse público que participou tão ativamente das 33 atividades que foram desenvolvidas entre os dias 16 e 18 de outubro de 2019. 
As respostas foram obtidas por meio de aplicação de questionário virtual, construído por meio da ferramenta Google Forms e enviado por e-mail, a todos os participantes das atividades do Festival da Primavera, entre 18 e 29 de novembro de 2019. Obteve-se, no total, 76 respondentes, entre eles 18 proponentes e 58 participantes.

Entre esse público é perceptível a presença intensa de estudantes do curso de Pedagogia, ofertado a distância pela Faculdade de Educação da UEMG, em convênio com a Prefeitura Municipal de Belo Horizonte (PMBH), Minas Gerais. Dos 76 participantes e proponentes respondentes: 19 foram desse segmento; 7 afirmaram que não se identificaram com nenhum dos vínculos apresentados; 1 respondente informou ser vinculado à Universidade Federal de Minas Gerais; e os 34 respondentes restantes confirmaram ter como vínculo os cursos presenciais da UEMG, conforme demonstrado no Gráfico 1.

Gráfico 1 - Vínculo dos participantes e dos proponentes respondentes

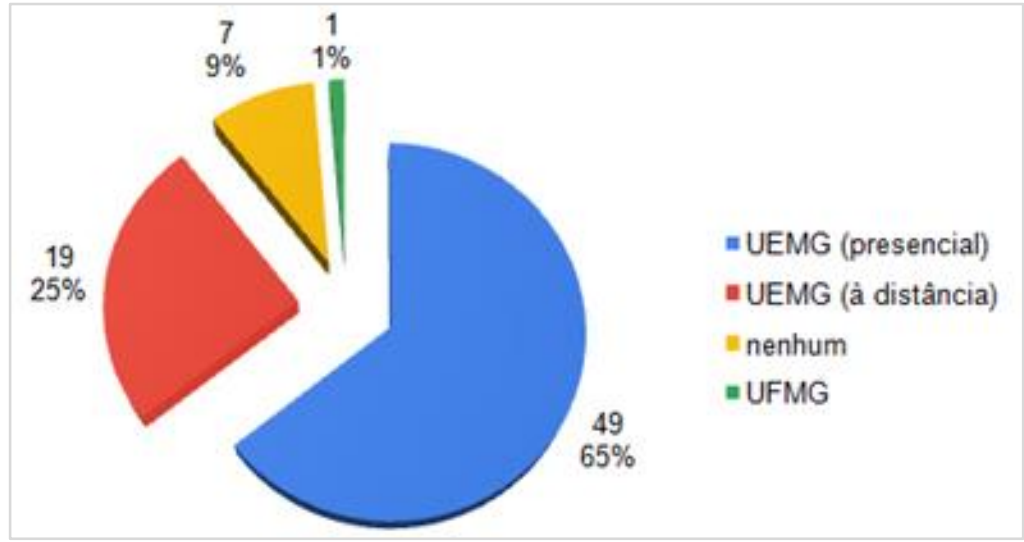

Fonte: Elaborado pelas autoras.

Por meio da análise de gênero dos respondentes, é possível perceber uma maioria do gênero feminino, tanto na participação quanto na proposição de atividades. Credita-se a isso o fato de que, por mais que fossem abertas a toda a Universidade, a maioria das atividades foi proposta por alunos e professores da Faculdade de Educação da UEMG, do curso de Pedagogia, que tem em sua generalidade a presença marcante do gênero feminino. 
Da faixa etária identificada na avaliação do Festival, observou-se: 1 respondente de 0 a 9 anos (o evento incentivou a presença de crianças, inclusive com programação específica); 5 respondentes de 10 a 19 anos; 22 respondentes de 20 a 29 anos; 15 respondentes de 30 a 39 anos; 21 respondentes de 40 a 49 anos; 9 respondentes de 50 a 59 anos; e 3 respondentes de 60 a 69 anos, conforme demonstrado no Gráfico 2.

Gráfico 2 - Faixa etária dos participantes e dos proponentes respondentes

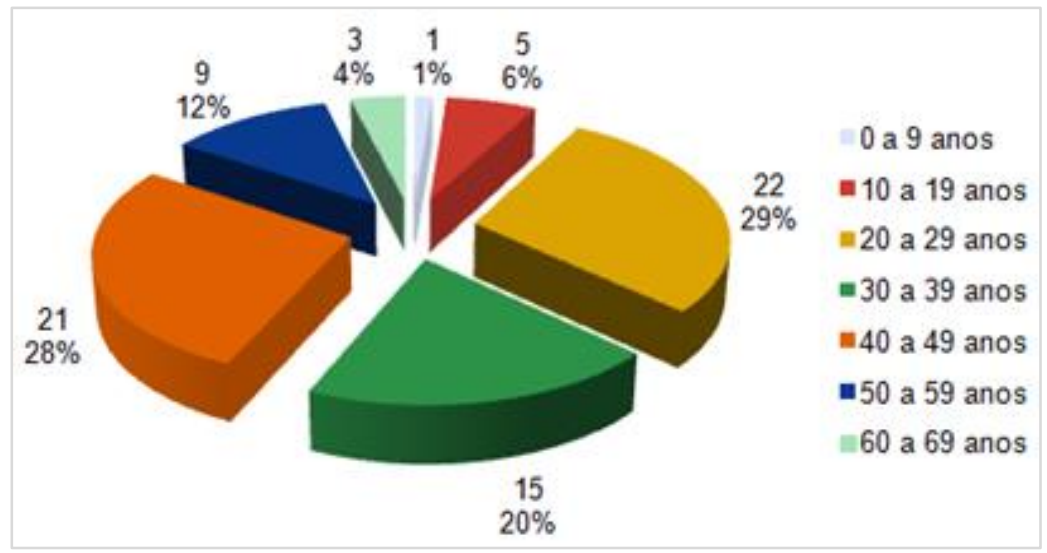

Fonte: Elaborado pelas autoras.

É importante salientar que é facilmente perceptível que não se teve a resposta de todos os participantes, pois foram emitidos mais certificados e constam mais assinaturas nas listas de presença do que a totalidade nesta pesquisa. A amostra aqui analisada será desse percentual de respostas, limitada à pesquisa no Google Forms. Com relação à faixa etária, é observada uma faixa média de idade de 40 a 60 anos, relativamente alta, com soma maior que a de 20 a 29 anos. Uma possibilidade para esta alta faixa etária é a presença significativa dos profissionais que já estão na área da Educação da PMBH e que hoje fazem o curso de Pedagogia em EaD, por meio de um Convênio entre a Universidade e a Prefeitura de Belo Horizonte, e que participaram tão ativamente do Festival, bem como outras atividades presenciais ofertadas pela Faculdade no decorrer do ano de 2019. 
Percebe-se que, por mais que a organização do evento tenha se empenhado na divulgação nas redes sociais, WhatsApp, emails e com cartazes pelas cidades onde se encontram às unidades da UEMG, os respondentes sinalizaram, em sua maioria (66 respondentes), que ficaram sabendo do evento e das atividades por meio dos colegas de sala e dos seus professores.

Percebe-se, também, presença de mais pessoas da Faculdade de Educação da UEMG como proponentes e participantes, pois, estando a organização lá, isso pode ter mobilizado mais estudantes da Unidade, apesar da presença de algumas propostas, em número menor, vindas de outras unidades da UEMG, inclusive das cidades do interior do estado de Minas Gerais.

No questionário aplicado, viu-se que 33 respondentes participaram de apenas uma atividade. Por outro lado, 43 respondentes fizeram mais de uma atividade proposta pelo Festival da Primavera no período de 3 dias - lembrando que, entre as respostas, tem-se o grupo que apenas participou como ouvinte, mas também os apresentadores das propostas, conforme demonstrado no Gráfico 3.

Gráfico 3 - Quantidade de atividades feitas pelos participantes

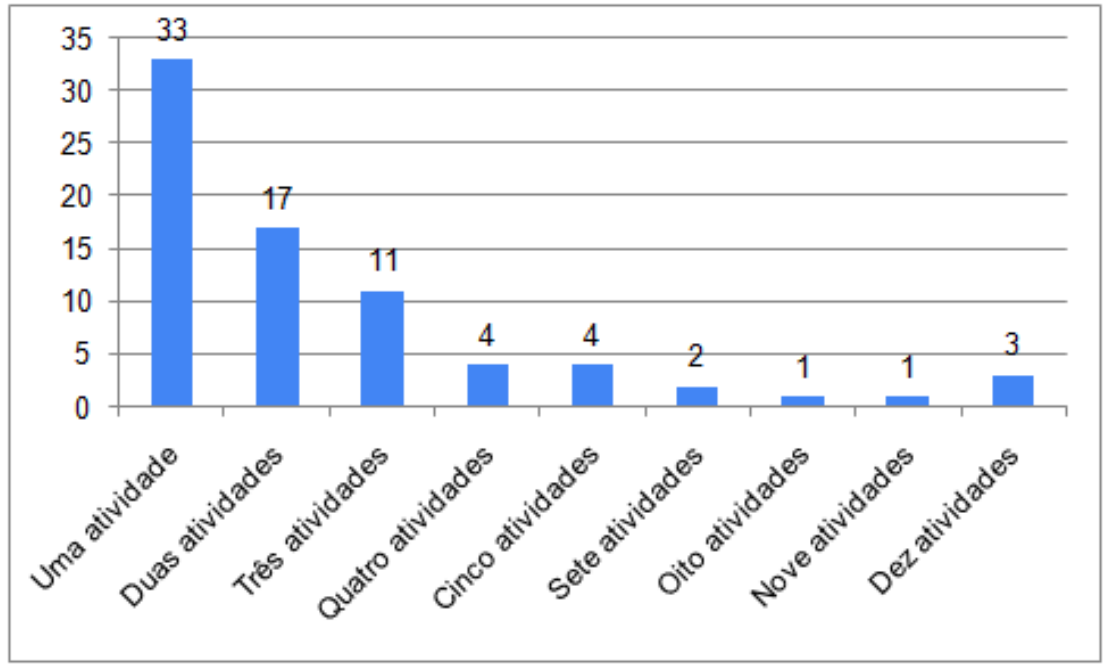

Fonte: elaborado pelas autoras. 
Não foram observadas diferenças significativas entre os proponentes e os ouvintes nas respostas dadas. No questionário de avaliação, perguntou-se a proponentes e participantes sobre sua percepção quanto à divulgação do evento, à programação, à organização, à relevância social e à indicação do evento a outras pessoas, além de duas perguntas com espaço aberto a respostas mais detalhadas, que indagavam sobre as atividades sugeridas para uma próxima edição e os comentários opcionais dos respondentes.

Quanto à organização do Festival, tivemos 56 classificações como Bom, 8 como Médio, 8 como Excelente e 4 como Fraco, conforme demonstrado no Gráfico 4.

Gráfico 4 - Avaliação dos participantes quanto à organização do evento

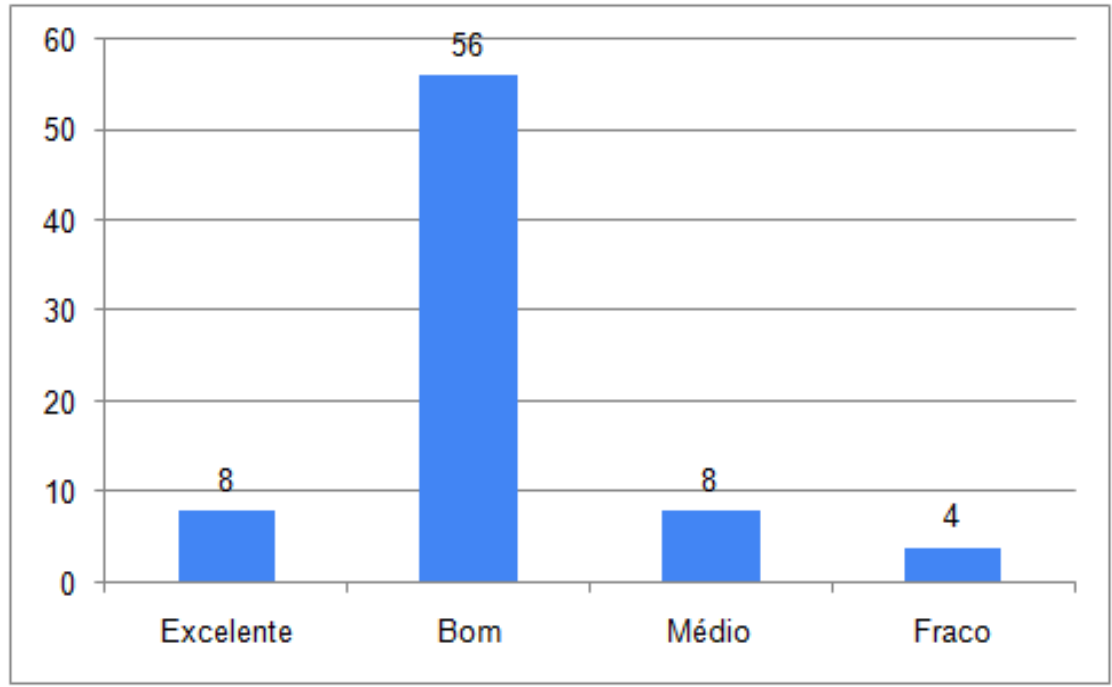

Fonte: elaborado pelas autoras.

Por meio das respostas, é possível perceber que a organização precisava realmente ter sido mais ampla. Considerando que o projeto partiu de um Núcleo de estudos da Faculdade de Educação, e que não foi fácil sensibilizar e chegar a todas as Unidades de forma equânime, verificou-se que isso reverberou na organização e também na divulgação do evento (como demonstrado no Gráfico 5), que se concentrou no lugar de sua 
realização, em Belo Horizonte, e acabou congregando mais às Unidades da capital, sobretudo, à FaE.

Gráfico 5 - Avaliação dos participantes quanto à divulgação do evento

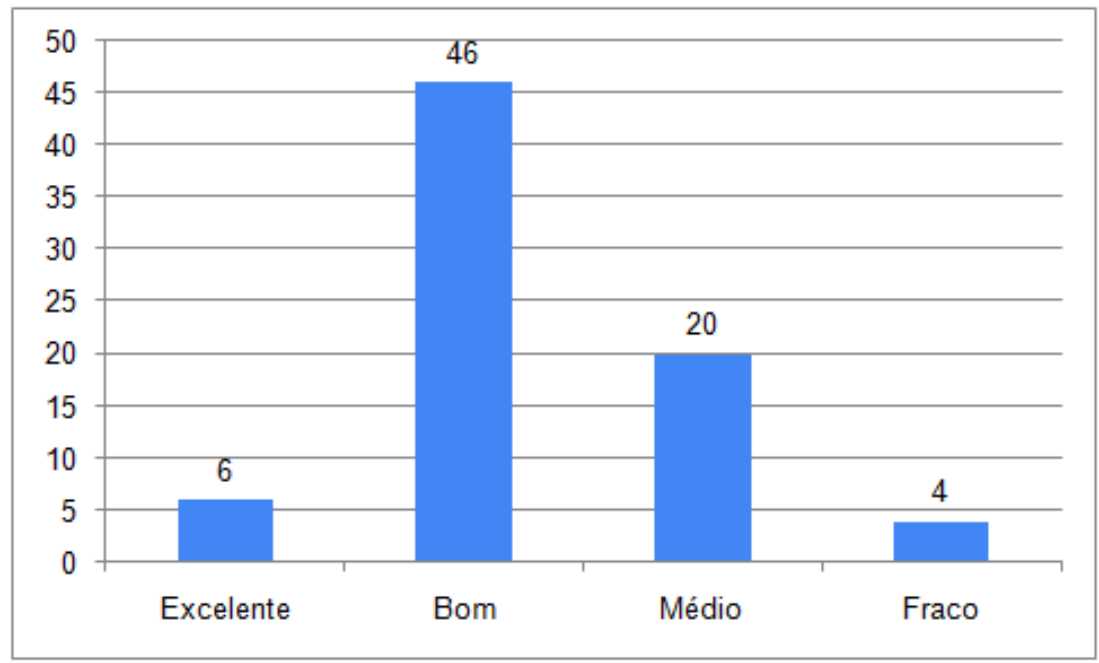

Fonte: Elaborado pelas autoras.

No que tange à programação do evento, 51 respondentes a classificaram como boa, 13 como média, 11 como excelente e 2 como fraca, como demonstrado no Gráfico 6. A programação foi construída por meio de edital aberto, para toda a UEMG, buscando a inclusão de propostas de estudantes, professores e funcionários. Também se teve a prevalência de temáticas relativas à educação, por conta da maior participação da $\mathrm{FaE}$, embora a organização também tenha convidado pesquisadores externos para apresentar seus trabalhos e oportunizado participações de caráter culturais, muito próprias de festivais universitários. 
Gráfico 6 - Avaliação dos participantes quanto à programação do evento

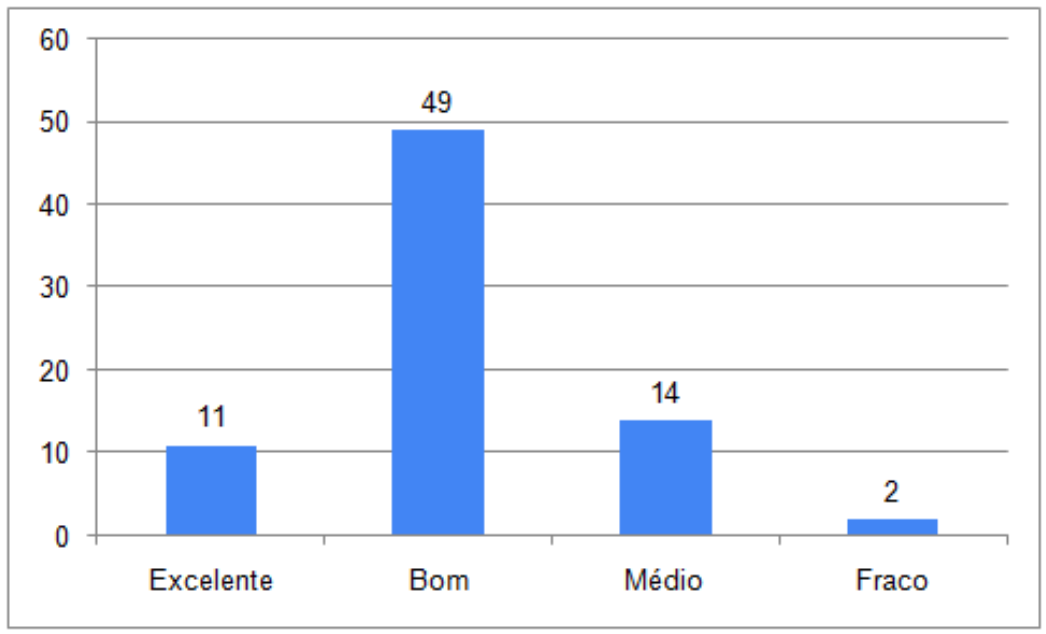

Fonte: Elaborado pelas autoras.

A grande maioria dos respondentes informou que indicaria o evento a outras pessoas, sendo que dos 76 respondentes, apenas 1 informou que não indicaria, justificando que percebeu o evento desorganizado.

Com relação à relevância social do evento, tem-se aqui um capítulo especial desta pesquisa. Entre os respondentes, 45 classificaram a relevância social do evento como Bom, 4 como Médio e 27 como Excelente. Aqui se teve o maior percentual positivo de respostas e o melhor nível de Excelente, sem nenhuma resposta tida como fraca - mesmo aquele único que não indicaria o evento respondeu que a relevância social do Festival era média. 
Gráfico 7 - Avaliação dos participantes quanto à relevância social do evento

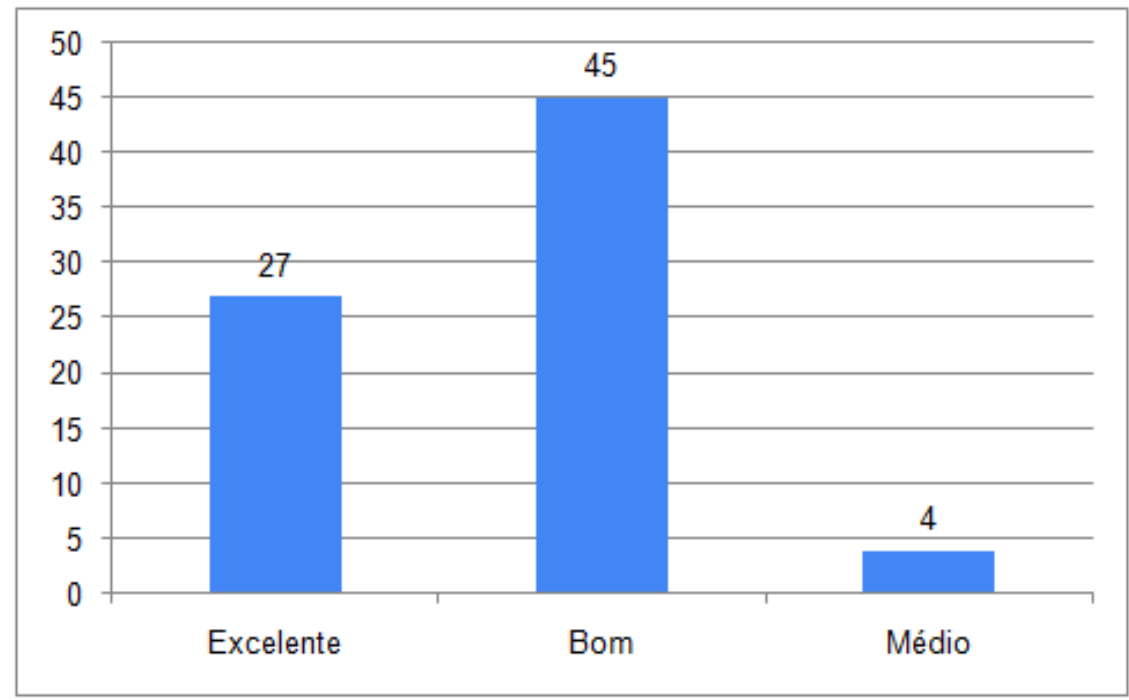

Fonte: Elaborado pelas autoras.

Percebe-se, dentro da Universidade, que os alunos muitas vezes têm uma visão que é pouco propositiva socialmente e que dialoga de forma superficial com a sociedade, de maneira geral, fazendo-se isolada e improdutiva no que tange ao cotidiano da vida social. Assim, foi possível visualizar, por meio desta pesquisa e de falas isoladas, acompanhadas durante a realização do Festival, que este evento fez com que os alunos enxergassem que a sociedade está dentro da Universidade também e que faz parte dela, sendo um ambiente propositivo e mais ativo - o que define a proposta do Festival. Isso está relacionado ao uso das representações sociais, como pontua Moscovici (2003). Por meio do questionário são perceptíveis as representações sociais elencadas sobre a finalidade da Universidade e sua importância no relevo social, a partir de mudanças de ações mais concretas do meio científico na sociedade.

Ao destacar e refletir sobre a presença de outros convidados externos para se apresentarem no Festival, além de incentivar a participação de crianças e demais pessoas que não são da Universidade no evento, é perceptível o caráter de exteriorização do conhecimento científico e social proposto pela academia científica 
para outros públicos e além de seus muros, como comentado anteriormente. Isso muda a representação social que a própria Universidade faz de si mesma. Rodrigues e outros (2013) salienta o papel fundamental que a extensão universitária fornece à sociedade:

É preciso, por parte da Universidade, apresentar concepção do que a extensão tem em relação à comunidade em geral. Colocar em prática aquilo que foi aprendido em sala de aula e desenvolvê-lo fora dela. A partir do momento em que há esse contato entre o aprendiz e a sociedade beneficiada por ele, acontece por parte dos dois lados, benefícios. Aquele que está na condição do aprender acaba aprendendo muito mais quando há esse contato, pois se torna muito mais gratificante praticar a teoria recebida dentro da sala de aula (RODRIGUES et al., 2013, p. 142).

Os respondentes foram categóricos ao escrever nas questões abertas sobre a importância dos próprios alunos e de professores apresentarem os seus trabalhos para outras pessoas, fora e dentro da Universidade, inclusive vindas de outras instâncias sociais. O papel da Universidade se consolida na extensão, quando, por meio dos festivais, por exemplo, o conhecimento produzido passa a ser socializado e discutido. A Universidade passa a ter importância no cenário social e nas representações sociais sobre ela mesma, ainda mais num período de discursos que são negativos sobre o meio científico, motivados pela ambiência política.

Moscovici (2003) afirma que "representar" é um processo de produção de conhecimento que funciona nas estruturas sociais e cognitivas locais, sendo variável a partir dos grupos envolvidos. As representações sociais daqueles ligados ao evento validam e conferem forte importância aos festivais, evidenciando sua qualidade de projeto educativo que congrega outros públicos e pessoas para dialogar sobre os conhecimentos que a Universidade pode produzir. Apesar dos contornos de mudança necessários nas próximas edições, o caráter de relevância que os participantes deram ao evento reitera a Universidade como fundamental ao desenvolvimento social,mesmo neste momento em que desponta a 
negação da Ciência e de contornos, como muitos afirmam, préiluministas.

Analisando as questões abertas do formulário de avaliação, verificou-se que apenas 27 respondentes deixaram comentários opcionais, sendo que destes podemos ressaltar alguns como positivos:

"O evento foi ótimo! Bem organizado estão de parabéns".

"O evento foi ótimo, precisa ser divulgado em mais espaços para que as pessoas apreciem o que tem sido feito na Universidade $e$ valorizem $o$ investimento na educação".

"Gostei muito do evento. Recomendo a outros que não puderam participar".

"Bom atendimento dos coordenadores; atenção por parte da maioria dos professores em assinar as fichas presenciais".

"Pontos positivos que podemos conhecer mais a nossa Universidade e conhecer alunos de outros turnos da nossa faculdade também, pessoas que da comunidade também participaram".

(Relatos dos respondentes no Google Forms em novembro de 2019).

E outros como negativos:

"Ponto negativo é que as pessoas se inscreveram e não compareceram, tirando a oportunidade de quem realmente tinha interesse, eu só consegui participar da Libras para Iniciantes porque faltou muita gente".

"O ponto negativo foi à falta de divulgação. Acho que a comunidade acadêmica deveria ter conhecido mais os oficineiros e participantes, suas biografias e propostas para que se fossem estimulados a participar".

(Relatos dos respondentes no Google Forms em novembro de 2019).

Percebe-se também a relevância de ouvir os participantes que trazem sugestões como estas: 
"Tenho percebido que divulgar as coisas pelo Instagram e Facebook não é suficiente. Tem que ter cartazes distribuídos pela cidade, pois redes sociais só circulam informação se houver muito dinheiro para patrocínio".

"Acho que fazer parcerias com escolas para levar turmas de alunos aos espaços pode funcionar bem melhor do que contar com público espontâneo, precisa ser dado mais tempo para divulgação da programação, dessa vez foi meio em cima da hora". "Nos próximos eventos poderia ter mais organização no sentido de pegar assinaturas para as atividades presenciais, pois ficamos rodando atrás de professores para assinarem nossas fichas presenciais, no mais foi tudo muito bom, palestras e palestrantes espetaculares. Amei".

"Integrar atividades acadêmicas, incluindo no cronograma para incentivar a participação de professores e estudantes".

(Relatos dos respondentes - Google Forms novembro de 2019).

\section{A falta de envolvimento dos professores da instituição foi lembrada por uma das participantes, quando esta escreveu o comentário a seguir.}

Gostei muito do evento, de participar, foi à primeira vez que propus algo na Faculdade, e nem imagina passar, foi muito bom... Mas confesso que fiquei desapontada, pois nenhum professor participou diretamente. Tive uma professora que pedi para ver a ideia e dar sugestões, mas, além disso, nada de especial. O professor $X^{5}$ esteve lá, deu uma olhada, mas não falou nada ou perguntou se precisava de algo. Mas também compreendo que houve muitas atividades simultâneas e não foi possivel participar de tudo. De modo geral, gostei muito do retorno, foi muito especial pra mim, principalmente como profissional em formação. Obrigada pela oportunidade :).

${ }^{5}$ Não será identificado por motivo de ética. 
(Relato de uma respondente no Google Forms em novembro de 2019).

Tal fato se deu, talvez, pela ocorrência do eventoem um período de recesso acadêmico, ou por ter sido proposto por um grupo específico de professores de uma Faculdade, e não pela Reitoria, ou ainda por não ter conseguido sensibilizar todos os professores quanto à importância desse tipo de evento, tanto para discentes e docentes quanto para a Universidade em si e para a cidade de Belo Horizonte como um todo.

Com relação à participação dos professores, a escala de acompanhamento de cada uma das atividades contemplou um monitor (estudante) e um grupo de três professores em cada dia, porém, de fato, não se tinha um professor para assessorar cada uma das atividades, porque eram muitas que ocorriam simultaneamente em cada dia.

Todas as atividades tinham um número de vagas que condiziam com o ambiente em que elas seriam desenvolvidas (de 20 a 150 vagas). As inscrições para cada uma das atividades foram realizadas por meio do site Sympla - plataforma on-line de eventos. Observou-se que muitos dos inscritos não compareceram às atividades e não justificaram a ausência, liberando, assim, suas vagas, aproveitadas por muitos participantes não inscritos que chegaram na hora.

Mesmo que somente uma criança tenha respondido o questionário (possivelmente com monitoria do responsável), teve-se na Faculdade de Educação e na Praça da Liberdade em Belo Horizonte a presença de muitas delas, em atividades recreativas e educativas destinadas ao público infantil. Foi realizada a divulgação do Festival em massa nas redes sociais, porém, pelas respostas é perceptível que os respondentes acharam necessária uma ampliação desta divulgação, o que mostra que o envolvimento maior das outras Unidades seria necessário. Além disso, muitos estudantes ficaram sabendo do Festival por meio de colegas e professores, que se mostrou como a maneira mais eficaz de divulgação.

Sobre os tipos de atividades ofertadas, os respondentes apontaram a multiplicidade de temas como algo positivo e pediram o reforço de temáticas relativas à inclusão, arte, tecnologia e 
educação. Das atividades propostas pelo Festival, aquelas que tiveram uma maior demanda foram às relativas à temática da Inclusão e da Educação. Uma aluna reforça e não somente ela, a importância do evento apresentar propostas dos estudantes:

\section{Positivo: Muitos alunos apresentando os seus trabalhos. \\ Dinamismo de conhecimento. \\ Negativo: horários vagos de uma apresentação para a outra. \\ (Relato de uma respondente no Google Forms em novembro de 2019).}

Quanto ao aspecto negativo apresentado pelo comentário transcrito anteriormente, não foi possível colocar atividades uma após a outra no Festival, durante os três dias, porque a organização seguiu a dinâmica de horário sugerida pelos proponentes. Em uma próxima edição do Festival, a organização pode tentar negociar mudanças, para facilitar o envolvimento de mais alunos, professores e da sociedade de forma geral em atividades que não sejam inclusive concomitantes.

Outra percepção foi a de que, por ser realizado em uma semana de recesso acadêmico, nem todos os estudantes e professores participaram. Contudo, por outro lado, se o evento acontecesse em um dia de aula regular, não haveria espaço físico para a realização das atividades (já que muitas ocorreram nos ambientes das Unidades). Um respondente indicou:

Penso que este tipo de evento deveria ser agendado em dias propícios à participação de mais pessoas.(Relato de um respondente no Google Forms em novembro de 2019).

Em contrapartida, muitos estudantes do curso de Pedagogia à distância, da parceria com a $\mathrm{PMBH}$, puderam permanecer o dia todo nas atividades, por ser uma semana de recesso escolar e estarem desobrigados de suas atividades laborais. É importante esclarecer que o Festival não contou com nenhum patrocínio, além de poucos recursos pré-existentes da Faculdade de Educação da UEMG. Entendeu-se, também, a importância de mais investimento 
financeiro de outros parceiros e mais institucionalidade da Universidade para a ampliação das atividades e do público, o que sanaria muitos dos problemas apresentados, como, por exemplo, a questão da ampliação da divulgação.

\section{CONSIDERAÇÕES FINAIS}

O I Festival da Primavera da UEMG congregou diversas atividades de caráter extensionista e de formação para alunos e pessoas externas, de outras instâncias sociais. Das atividades promovidas nos três dias de evento, teve-se uma presença significativa de alunos, principalmente da Faculdade de Educação da UEMG - a organizadora. Atividades relacionadas à inclusão, à arte, à recreação, à tecnologia, à educação, entre outras, fizeram parte do evento, que incluiu apresentações de trabalhos de professores e alunos da UEMG, além de convidados externos.

No questionário de avaliação enviado aos proponentes e participantes e analisado no presente artigo, observou-se alguns elementos fundamentais para a organização, o planejamento, a divulgação e a realização do evento, elementos estes que poderão ser de grande valia para a execução de futuros projetos. Mesmo que a divulgação e a organização não tivessem a totalidade da anuência dos participantes, que foi, em sua maioria, positiva, a relevância social do evento tem destaque. A Universidade, em um momento crítico de sua legitimação social, conseguiu angariar e veicular representações sociais positivas no seu papel de cumpridora agente social de produção e disseminação de conhecimentos.

A programação que constou de atividades que os alunos sugeriram foi destaque nas respostas. Conhecer o que se produz por outros grupos de estudantes na mesma Universidade, quais trabalhos estes realizam e se engajar também como voluntários num evento desta magnitude marcou a opinião dos alunos. Os estudantes se sentem partícipes de sua história na Universidade quando se tornam agentes do saber, além de colocarem-se no lugar da docência, ao apresentarem seus trabalhos. Essa é uma forma de inclusão e valorização do educando e do sujeito da aprendizagem. 
Conclui-se que uma das questões a ser aprimorada nos próximos eventos e projetos deste caráter é a comunicação interna entre a Universidade e as outras Unidades, um problema maior vivenciado em nossa instituição, por esta ser multicampi e não estar presente em apenas uma cidade. A realização desse Festival em conjunto com as outras Unidades e cidades e o financiamento de parceiros para o fornecimento de materiais, mídias, divulgação, para além dos recursos da Universidade (que não são muitos) podem ampliar os raios de ação desse evento extensionista, que encoraja práticas inovadoras na relação de aprendizagem e no papel amplificado da Universidade.

\section{REFERÊNCIAS}

AGOSTINI, R. MEC cortará verba de universidade por "balbúrdia" e já enquadra UnB, UFF e UFBA. Estadão, 30 abr. 2019. Disponível em: https://educacao.estadao.com.br/noticias/geral,mec-cortara-verbade-universidade-por-balburdia-e-ja-mira-unb-uff-eufba,70002809579. Acesso em: 20 abr. 2020.

\section{BREDARIOLLI, R. L. B. XIV Festival de Inverno de Campos de}

Jordão: variações sobre temas de ensino da arte. 2009. Tese (Doutorado) - Escola de Comunicação e Artes, Universidade de São Paulo, São Paulo, 2009.

GONÇALVES, N. G. Indissociabilidade entre Ensino, Pesquisa e Extensão: um princípio necessário. Perspectiva, Florianópolis/SC, v. 33, n. 3, p. 1229-1256, set./dez. 2015.

KAMINSKI, L. F. Teatro, liberdade e repressão nos Festivais de Inverno de Ouro Preto - 1967-1979. Varia História, v. 32, n. 59, p. 327-355, maio/ago. 2016.

LEITE, M. Governo Bolsonaro coloca a ciência nas trincheiras. Folha de S.Paulo. 14 ago. 2019. Disponível em: https://www1.folha.uol.com.br/colunas/marceloleite/2019/08/gover no-bolsonaro-coloca-a-ciencia-nas-trincheiras.shtml. Acesso em: 20 abr. 2020. 
MOSCOVICl, S. Representações sociais: investigações em psicologia social. Rio de Janeiro: Vozes, 2003.

REIS, A. M. S; BOMFIM, N. R. Representações Sociais da Comunidade sobre o Festival de Inverno de Ouro Preto, Minas Gerais (Brasil) a partir da Evocação Livre de Palavras. Turismo \& Sociedade, Curitiba/PR, v. 5, n. 1, p. 252-274, abr. 2012.

RODRIGUES, A. L. L. et al. Contribuições na extensão universitária na sociedade. Cadernos de Graduação, Ciências Humanas e Sociais, Aracaju/SE, v. 1, n. 16, mar. 2013.

UEMG - Universidade do Estado de Minas Gerais. Festival da Primavera da UEMG: inscrições abertas. UEMG. 03/10/2019a.

Disponível em: https://drive.google.com/file/d/1EM3ikIYPC4YuVEmhJvozT_JW4KHT43a/view. Acesso em: 21 mar. 2021.

UEMG - Universidade do Estado de Minas Gerais. I Festival da Primavera da UEMG. UEMG. 09/08/2019b. Disponível em: http://uemg.br/component/phocadownload/category/376-festivalda-primavera-da-uemg-2019. Acesso em: 21 mar. 2021.

UEMG - Universidade do Estado de Minas Gerais. Sobre a UEMG. UEMG. 01/02/2019c. Disponível em:

http://uemg.br/home/universidade/sobre-a-uemg. Acesso em: 18 jun. 2020.

Submetido em: Agosto/ 2020.

Aceito em: Fevereiro/ 2021. 